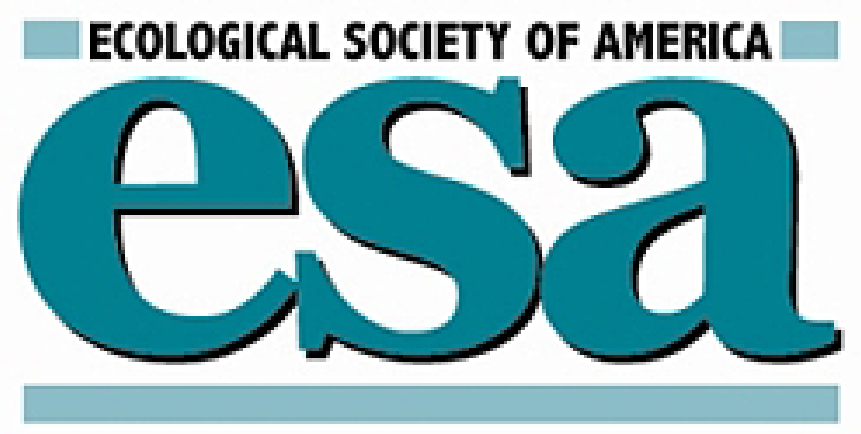

The Cost of Reproduction and Experience-Dependent Vital Rates in a Small Petrel Author(s): Ana Sanz-Aguilar, Giacomo Tavecchia, Roger Pradel, Eduardo Mínguez and Daniel Oro

Source: Ecology, Vol. 89, No. 11 (Nov., 2008), pp. 3195-3203

Published by: Ecological Society of America

Stable URL: http://www.jstor.org/stable/27650874

Accessed: 01/07/2014 07:45

Your use of the JSTOR archive indicates your acceptance of the Terms \& Conditions of Use, available at http://www.jstor.org/page/info/about/policies/terms.jsp

JSTOR is a not-for-profit service that helps scholars, researchers, and students discover, use, and build upon a wide range of content in a trusted digital archive. We use information technology and tools to increase productivity and facilitate new forms of scholarship. For more information about JSTOR, please contact support@jstor.org. 


\title{
THE COST OF REPRODUCTION AND EXPERIENCE-DEPENDENT VITAL RATES IN A SMALL PETREL
}

\author{
Ana Sanz-Aguilar, ${ }^{1,4}$ Giacomo Tavecchia, ${ }^{1}$ Roger Pradel, ${ }^{1,2}$ Eduardo Mínguez, ${ }^{3}$ and Daniel Oro ${ }^{1}$ \\ ${ }^{1}$ Institut Mediterrani d'Estudis Avancats IMEDEA (CSIC-UIB), Miquel Marqués 21, 07190 Esporles, Mallorca, Spain \\ ${ }^{2}$ Centre d'Ecologie Fonctionnelle et Evolutive (CNRS), 1919 Route de Mende, UMR 5175 Montpellier, France \\ ${ }^{3}$ Parque Natural Serra Gelada y su entorno litoral (Generalitat Valenciana), Paseo de la Carretera 34, \\ 03501 Benidorm, Alicante, Spain
}

\begin{abstract}
Life history theory predicts that higher levels of reproductive investment entail higher reproductive costs especially among young and inexperienced individuals that might not optimize reproductive investment. Using a long-term individual and state-dependent capture-recapture data on Storm Petrels (Hydrobates pelagicus) we analyzed whether breeding experience and current breeding investment were associated with the expression of the cost of reproduction in terms of reduced survival and/or future breeding performance. We found a positive relationship between current breeding investment, breeding experience, and future survival and an improvement in breeding performance with individual experience independently of the previous breeding outcome. Our results suggest that the survival cost paid by first-time breeders and the positive correlation between reproduction and survival corresponds to selection against low quality birds unrelated to the breeding effort. Our work outlines the need to investigate the effect of multiple individual traits on different life history trade-offs simultaneously.
\end{abstract}

Key words: breeding experience; breeding success; demography; multistate capture-recapture analysis; Procellariiformes; reproductive cost; survival probability.

\section{INTRODUCTION}

Trade-offs, defined as the negative correlations between traits that constrain their simultaneous evolution, constitute one of the central topics in the life history theory (Fox et al. 2001). Such theory postulates the cost of reproduction hypothesis, which predicts a negative covariation between the effort in the current reproduction and the future survival and/or fecundity (Roff 1992, Stearns 1992, McNamara and Houston 1996). In long-lived species, in which individual fitness is dominated by the high survival rate, a cost of reproduction is expected to be evident on fecundity and not on future survival (Roff 1992, Crone 2001). An extreme example are the long-lived seabirds of the order Procellariiformes that are characterized by very high annual adult survival rates, deferred breeding, and low reproductive output (Warham 1990, 1996). In these species, the population growth rate is highly sensitive to small changes of adult survival probability (Saether and Bakke 2000). Moreover, it has been suggested that parental effort in Procellariiformes is regulated to a fixed investment, independently of offspring needs (Navarro and González-Solís 2007). Potential costs of reproduction are thus expected to be buffered by adjustments in current breeding performance through, for example, reproductive skipping or nest desertion during adverse

Manuscript received 29 February 2008; accepted 13 March 2008. Corresponding Editor: E. G. Cooch.

${ }^{4}$ E-mail: ana.sanz@uib.es environmental conditions (Erikstad et al. 1998, Wernham and Bryant 1998, Orzack and Tuljapurkar 2001, Jenouvrier et al. 2005).

Because optimal reproductive investment can mask the negative correlation between traits, evidence of the cost of reproduction is generally derived from experimental studies in which individuals are forced to increase or reduce their current reproductive investment (Reznick 1985, 1992, Stevenson and Bancroft 1995; but see Doligez et al. 2002). In non-manipulative studies, reproductive costs may not be visible because individuals would invest according to their resources or intrinsic quality (Van Noordwijk and Dejong 1986, Erikstad et al. 1998, Reznick et al. 2000) leading to positive correlations between fitness components at the population level, i.e., the selection hypothesis (Cam and Monnat 2000, Cam et al. 2002, Mauck et al. 2004, Blums et al. 2005, Tavecchia et al. 2005, Barbraud and Weimerskirch 2006). Nonetheless, in some cases, longterm correlative studies based on detailed information on a sufficiently large number of individuals, provide evidence of a reproductive cost (Moyes et al. 2006), typically under severe environmental conditions (Tavecchia et al. 2005, Nevoux et al. 2007), during the firstbreeding attempt (Cam and Monnat 2000, Barbraud and Weimerskirch 2005), or in the first years of life (Tavecchia et al. 2001)

The first-breeding attempt in particular has been shown to be a critical period during which a cost of reproduction may be evident (Cam and Monnat 2000). 
In fact, first-time breeders have regularly been shown to exhibit a lower probability of breeding successfully (Weimerskirch 1990, Barbraud and Weimerskirch 2006, Nevoux et al. 2007), a lower local survival or return rate than experienced breeders (Pyle et al. 1997, Bradley et al. 2000, Barbraud and Weimerskirch 2005, Nevoux et al. 2007) and a higher probability of non-breeding the following year (Coulson and Thomas 1985, Weimerskirch 1990, Viallefont et al. 1995, Cam and Monnat 2000, Barbraud and Weimerskirch 2005). At the individual level, these costs can be mediated by metabolic and regulatory signals triggered by the first reproduction (Harshman and Zera 2007) or simply by a lack of breeding experience, i.e., partner bond or ability to sustain long incubation periods (i.e., the breeding experience hypothesis [Ollason and Dunnet 1988, Bradley et al. 2000]). However, first-time breeders are on average younger than experienced breeders, and both lack of breeding experience and age can affect individuals simultaneously (Bradley et al. 2000, Cam and Monnat 2000, Tavecchia et al. 2001, Ratcliffe et al. 2002, Reid et al. 2003, Moyes et al. 2006). There are clearly strong challenges to studying the cost of reproduction from correlative studies. For example, in trying to separate the effects of experience from that of age, one ideally needs the complete information on the past breeding attempts of known-aged individuals. This information is obviously rarely found, especially for a large number of individuals. Also, in natural populations the probability of detection needs to be taken into account to obtain unbiased estimates of survival and other similar demographic parameters (Boulinier et al. 1997).

Here we analyze (1) the experience-dependent cost of reproduction in terms of breeding performance at individual level and (2) future survival and future reproduction at population level in the European Storm Petrel Hydrobates pelagicus. Storm Petrels are small (average weight $28 \mathrm{~g}$ ) and long-lived Procellariiformes with an extended breeding period (incubation lasts about 40 days and chick rearing about $63-70$ days). They lay a single and proportionally large egg $(\sim 30 \%$ of adult body mass) and their chicks reach a body mass $\sim 130 \%$ that of adults (Warham 1990, Mínguez 1996, 1998). Their breeding effort invested in natural conditions is potentially costly and suitable to evaluate the trade-off between reproductive investment and survival. We used a long-term detailed stratified data and multistate capture-recapture models to measure the influence of the current reproduction on future survival and fecundity by modeling simultaneously survival, between-states transitions and detection probability (Nichols et al. 1994, Nichols and Kendall 1995). Such models are suitable to test how survival and future breeding probability change according to the current breeding investment in the context of capture-recapture studies where observations are incomplete (Nichols and Kendall 1995). At the moment, these types of models cannot take into account the difference in intrinsic quality among individuals but, if individual heterogeneity may mask or reduce the observed magnitude of the trade-off, it cannot fake it. Hence, in correlative studies, the absence of a correlation between traits cannot be considered as strong support for their independence, but a negative correlation is an indication of a phenotypic link between the traits (Nur 1988)

\section{Methods}

\section{Study area}

The study was conducted at Benidorm Island, a 6.5-ha Special Protection Area for the conservation of the European Storm Petrel, on the Mediterranean coast of Spain $\left(38^{\circ} 30^{\prime} \mathrm{N}, 0^{\circ} 8^{\prime} \mathrm{E}\right)$. Here breeding petrels concentrate in two caves where they nest at high densities. One colony (cave 1, hereafter) contains over 200 breeding pairs whereas the other colony (cave 2, hereafter) is home to approximately 100 breeding pairs (Mínguez 1994). In 1996, a number of artificial nest boxes were installed inside both colonies but they were principally occupied in cave 2 only (de León and Mínguez 2003). Each year, breeding birds were caught only once, during the incubation period. However, each nest was inspected at least four times during the whole breeding period to record individual breeding success. Breeding adults caught in their nest were marked with stainless steel rings with a unique alphanumeric code. No ring degradation was ever recorded and we assumed that metal ring loss is negligible.

\section{Stratified observations}

We considered 1657 observations of 639 breeding birds captured in their nests during the period 19942006 in cave 1 and during 1995-2006 in cave 2 . Observations were first classified according to individual known breeding experience. Individuals captured for the first time in nests monitored in previous occasions were classified as first-time breeders (FTB hereafter), whereas individuals previously recorded as breeders were classified as experienced breeders (EB hereafter). Observations on individuals captured for the first time in nests that were not monitored previously were discarded. As found in other studies, the breeding tenacity was extremely high and only 12 birds have changed nest during the study period. For this reason birds were unlikely to be missed as a consequence of local breeding dispersal. Breeding dispersal to the other colony was also very rare and individuals caught in one colony have never been observed in the other one, with the exception of one case (deleted in the current analysis). Nonetheless, there are instances when a nest was known to be occupied but the bird has not been captured. Thus, capture failures were not necessarily associated with empty nests. To summarize, breeding dispersal and reproductive skipping were negligible in both colonies, consequently, recapture probability does not reflect breeding frequency. Note that here immature animals, 
i.e., individuals that have not bred yet, were never considered. Observations of breeding birds were stratified in "unsuccessful" or "successful," according to the breeding success at the end of the current breeding occasion. Individuals failing to hatch or to rear a chick were considered unsuccessful. The breeding success was considered as an individual state allowing transitions between its two levels at any time interval. Individuals were also classified in relation to the breeding colony (cave 1 or cave 2), but no movements between these two levels were allowed. Each individual first caught as firsttime breeder became automatically experienced breeder in the next occasion so that animals do not remain firsttime breeder from more than one occasion.

\section{Statistical analysis and model notation}

Current breeding success.-The effect of experience on the current breeding success was examined using generalized linear mixed models (McCulloch and Searle 2001). We analyzed a total of 1657 breeding outcomes, 288 of which from first-time breeders. The breeding output was treated as a binary variable $(1=$ successful, 0 $=$ unsuccessful) and modeled as a function of bird experience using the glmmML function in the statistical package $\mathrm{R}$ (available online). ${ }^{5}$ The individual identity was treated as a random effect to control for multiple contributions made by the same individual.

Survival and future breeding success.-We evaluated the influence of the colony, individual breeding experience and current breeding success state on survival and future breeding success probabilities. To do this, observations were written in multistate encounter-histories and analyzed using multistate capture-recapture models (Brownie et al. 1993, Lebreton and Pradel 2002) with the program M-SURGE (Choquet et al. 2004). These models include three types of parameters for each colony (Nichols et al. 1994), noted and defined as follows:

$p_{t}^{r}$, the probability that a marked bird is recaptured at time $t$ in state $r$, given that it is alive and present in the population at time $t$. The two possible states are unsuccessful and successful breeder.

$\Phi_{t}^{r}$, the probability that a bird in state $r$ at time $t$ survives until $t+1$.

$\Psi_{t}^{r s}$, the probability that a bird in state $r$ at time $t$ is in state $s$ at $t+1$, given that the individual survived from time $t$ to time $t+1$. Note that this probability is conditional to survival.

These three parameters were estimated simultaneously from encounter histories by maximum likelihood procedure (Choquet et al. 2004). Program M-SURGE additionally provides automatically the model rank, i.e., the number of separately identifiable parameters, and accounts for the rank and data to compute the Akaike's Information Criterion (Choquet et al. 2004). The nonidentifiable parameters are also listed individually.

\footnotetext{
${ }^{5}\langle$ www.R-project.org/〉
}

TABLE 1. The role of breeding experience in the breeding success of European Storm Petrels at Benidorm Island (western Mediterranean).

\begin{tabular}{clccccc}
\hline \hline Model & \multicolumn{1}{c}{ Effect } & np & Dev & AIC & $\Delta i$ & $w_{i}$ \\
\hline $\mathbf{1}$ & FTB, EB & $\mathbf{2}$ & $\mathbf{2 2 4 1}$ & $\mathbf{2 2 4 7}$ & $\mathbf{0}$ & $\mathbf{0 . 9 9 8}$ \\
2 & no effects considered & 1 & 2256 & 2260 & 13 & 0.002
\end{tabular}

Notes: "FTB" and "EB" denote the effect of the breeding Notes: "FTB" and "EB" denote the effect of the breeding
experience and its two levels, first-time breeder and experienced breeder, respectively. Abbreviations are: np, number of parameters; Dev, relative deviance; AIC, Akaike information criterion; $\Delta_{i}$, the AIC difference between the current and lowest AIC model; $w_{i}$, Akaike weight. The retained model is in boldface type.

Multistate models do not distinguish mortality from permanent emigration and survival should be considered as local (Lebreton et al. 1992). The general model we began with is equivalent to the traditional ArnasonSchwarz model (Schwarz et al. 1993) extended to two groups, i.e., colony 1 and 2 , and with two apparent "age classes," i.e., first-time and experienced breeder. We began to model recapture, survival, and transitions processes by the following general model:

$$
p_{t \times \text { cave } \times \mathrm{bs}}, \Phi_{t \times \exp \times \mathrm{bs} \times \text { cave }}, \Psi_{\mathrm{bs} \times t \times \exp \times \text { cave }}
$$

assuming for survival, $\Phi$, and transition, $\Psi$, probabilities an effect of the colony, noted "cave," the year, noted " $t$," the experience, noted "exp," and the breeding success state, noted "bs." In this model the probability of recapture, $p$, varied according to the colony, the year, and the breeding success state. We refer to this general model as the "umbrella model." The goodness of fit of the umbrella model was assessed through contingency tables using program U-CARE 2.2.2 (Pradel et al. 2003, Choquet et al. 2005). The effect of the experience was not considered in the umbrella model nor in any other model as predictor of $p$ because this parameter refers to the recapture probability of birds after the marking and by this time first-time breeders have become experienced breeders. Note also that most captures occurred during the incubation period when failed breeders were still present, consequently the breeding success cannot be associated with the recapture probability. It was, however, included in the umbrella model because the only goodness of fit test available is for a model including all effects on all parameters, i.e., the umbrella model. Model selection was based on Akaike information criterion (AIC) and the Akaike weights ( $w_{i}$, for each model $i$ ) were calculated as an index of the relative plausibility of each model. Estimates of $\Phi$ and $\Psi$ were obtained by model averaging in which each model contributed to the final estimate according to its Akaike weight (Burnham and Anderson 2000). The importance of a particular effect can be refined by making inference from all models in the candidate set. Akaike weights, $w$, were summed for all models containing the effect considered. The effect with the largest sum of $w$, denoted $w+$, was considered to be the most important (Burnham 
TABLE 2. Estimation of recapture $(p)$, yearly survival $(\Phi)$, and future breeding performance ( $\Psi$ ) probabilities of European Storm Petrels breeding at Benidorm Island (western Mediterranean) by multistate capture-recapture modeling.

\begin{tabular}{|c|c|c|c|}
\hline \multirow[b]{2}{*}{ Model } & \multicolumn{3}{|c|}{ Considered effects in $p, \Phi$, and $\Psi$} \\
\hline & $p$ & $\Phi$ & $\Psi$ \\
\hline \multicolumn{4}{|c|}{ Modeling recapture probabilities } \\
\hline Umbrella & $t \times$ cave $\times$ bs & $t \times \exp \times$ bs $\times$ cave & bs $\times t \times \exp \times$ cave \\
\hline 1 & $t \times$ cave & $t \times \exp \times$ bs $\times$ cave & bs $\times t \times \exp \times$ cave \\
\hline 2 & $t+$ cave & $t \times \exp \times$ bs $\times$ cave & bs $\times t \times \exp \times$ cave \\
\hline 3 & $t \times \mathrm{c} 1$, linear variation in $t \times \mathrm{c} 2$ & $t \times \exp \times$ bs $\times$ cave & bs $\times t \times \exp \times$ cave \\
\hline 4 & $t$ & $t \times \exp \times$ bs $\times$ cave & bs $\times t \times \exp \times$ cave \\
\hline 5 & cave & $t \times \exp \times$ bs $\times$ cave & bs $\times t \times \exp \times$ cave \\
\hline \multicolumn{4}{|c|}{ Modeling survival probabilities } \\
\hline 6 & $t \times \mathrm{c} 1$, linear variation in $t \times \mathrm{c} 2$ & $t+\exp +\mathrm{bs}+$ cave & bs $\times t \times \exp \times$ cave \\
\hline 7 & $t \times \mathrm{cl}$, linear variation in $t \times \mathrm{c} 2$ & $t \times \exp \times$ bs & bs $\times t \times \exp \times$ cave \\
\hline 8 & $t \times \mathrm{c} 1$, linear variation in $t \times \mathrm{c} 2$ & $t+\exp +b s$ & bs $\times t \times \exp \times$ cave \\
\hline 9 & $t \times \mathrm{c} 1$, linear variation in $t \times \mathrm{c} 2$ & $t+[\exp \times$ bs $]$ & bs $\times t \times \exp \times$ cave \\
\hline 10 & $t \times \mathrm{c} 1$, linear variation in $t \times \mathrm{c} 2$ & $t+\mathbf{F T B}+[\mathbf{E B} \times \mathbf{b s}]$ & bs $\times t \times \exp \times$ cave \\
\hline 11 & $t \times \mathrm{c} 1$, linear variation in $t \times \mathrm{c} 2$ & $t+\mathrm{EB}+[\mathrm{FTB} \times \mathrm{bs}]$ & bs $\times t \times \exp \times$ cave \\
\hline 12 & $t \times \mathrm{c} 1$, linear variation in $t \times \mathrm{c} 2$ & $t+\exp$ & bs $\times t \times \exp \times$ cave \\
\hline 13 & $t \times \mathrm{cl}$, linear variation in $t \times \mathrm{c} 2$ & $t+\mathrm{bs}$ & bs $\times t \times \exp \times$ cave \\
\hline 14 & $t \times \mathrm{cl}$, linear variation in $t \times \mathrm{c} 2$ & $\exp +\mathrm{bs}$ & bs $\times t \times \exp \times$ cave \\
\hline \multicolumn{4}{|c|}{ Modeling future breeding success probabilities } \\
\hline 15 & $t \times \mathrm{c} 1$, linear variation in $t \times \mathrm{c} 2$ & $t \times \exp \times$ bs $\times$ cave & bs $\times[t+\exp +$ cave $]$ \\
\hline 16 & $t \times \mathrm{c} 1$, linear variation in $t \times \mathrm{c} 2$ & $t \times \exp \times$ bs $\times$ cave & bs $\times t \times \exp$ \\
\hline 17 & $t \times \mathrm{c} 1$, linear variation in $t \times \mathrm{c} 2$ & $t \times \exp \times$ bs $\times$ cave & $\mathrm{bs} \times[t+\exp ]$ \\
\hline 18 & $t \times \mathrm{c} 1$, linear variation in $t \times \mathrm{c} 2$ & $t \times \exp \times$ bs $\times$ cave & $\mathrm{bs}+t+\exp$ \\
\hline 19 & $t \times \mathrm{c} 1$, linear variation in $t \times \mathrm{c} 2$ & $t \times \exp \times$ bs $\times$ cave & $t \times[\mathrm{FTB}+\mathrm{EB} \times \mathrm{bs}]$ \\
\hline 20 & $t \times \mathrm{c} 1$, linear variation in $t \times \mathrm{c} 2$ & $t \times \exp \times$ bs $\times$ cave & $t \times[\mathbf{E B}+\mathbf{F T B} \times \mathbf{b s}]$ \\
\hline 21 & $t \times \mathrm{c} 1$, linear variation in $t \times \mathrm{c} 2$ & $t \times \exp \times$ bs $\times$ cave & $t+\mathrm{EB}+\mathrm{FTB} \times \mathrm{bs}$ \\
\hline 22 & $t \times \mathrm{c} 1$, linear variation in $t \times \mathrm{c} 2$ & $t \times \exp \times$ bs $\times$ cave & $\mathrm{bs} \times t$ \\
\hline 23 & $t \times \mathrm{c} 1$, linear variation in $t \times \mathrm{c} 2$ & $t \times \exp \times$ bs $\times$ cave & $\mathrm{bs}+t$ \\
\hline 24 & $t \times \mathrm{cl}$, linear variation in $t \times \mathrm{c} 2$ & $t \times \exp \times$ bs $\times$ cave & bs $\times \exp$ \\
\hline 25 & $t \times \mathrm{c} 1$, linear variation in $t \times \mathrm{c} 2$ & $t \times \exp \times$ bs $\times$ cave & $t \times \exp$ \\
\hline 26 & $t \times \mathrm{cl}$, linear variation in $t \times \mathrm{c} 2$ & $t \times \exp \times$ bs $\times$ cave & $t+\exp$ \\
\hline 27 & $t \times \mathrm{cl}$, linear variation in $t \times \mathrm{c} 2$ & $t \times \exp \times$ bs $\times$ cave & $t$ \\
\hline 28 & $t \times \mathrm{c} 1$, linear variation in $t \times \mathrm{c} 2$ & $t \times \exp \times$ bs $\times$ cave & $\exp$ \\
\hline 29 & $t \times \mathrm{cl}$, linear variation in $t \times \mathrm{c} 2$ & $t \times \exp \times$ bs $\times$ cave & bs \\
\hline 30 & $t \times \mathrm{cl}$, linear variation in $t \times \mathrm{c} 2$ & $t \times \exp \times$ bs $\times$ cave & no effects considered \\
\hline \multicolumn{4}{|l|}{ Final models } \\
\hline 31 & $t \times \mathrm{c} 1$, linear variation in $t \times \mathrm{c} 2$ & $t+\exp +\mathbf{b s}$ & $\mathbf{t} \times[\mathrm{EB}+\mathrm{FTB} \times \mathrm{bs}]$ \\
\hline 32 & $t \times \mathrm{c1}$, linear variation in $t \times \mathrm{c} 2$ & $t+[\exp \times$ bs $]$ & $t \times[\mathrm{EB}+\mathrm{FTB} \times \mathrm{bs}]$ \\
\hline 33 & $t \times \mathrm{c} 1$, linear variation in $t \times \mathrm{c} 2$ & $t+\mathbf{F T B}+[\mathbf{E B} \times \mathbf{b s}]$ & $t \times[\mathbf{E B}+\mathbf{F T B} \times \mathbf{b s}]$ \\
\hline 34 & $t \times \mathrm{c} 1$, linear variation in $t \times \mathrm{c} 2$ & $t+\exp +\mathrm{bs}$ & $\mathrm{EB}+\mathrm{FTB} \times$ bs \\
\hline 35 & $t \times \mathrm{cl}$, linear variation in $t \times \mathrm{c} 2$ & $t+[\exp \times \mathrm{bs}]$ & $\mathrm{EB}+\mathrm{FTB} \times \mathrm{bs}$ \\
\hline 36 & $t \times \mathrm{c} 1$, linear variation in $t \times \mathrm{c} 2$ & $t+\mathrm{FTB}+[\mathrm{EB} \times \mathrm{bs}]$ & $\mathrm{EB}+\mathrm{FTB} \times \mathrm{bs}$ \\
\hline 37 & $t \times \mathrm{cl}$, linear variation in $t \times \mathrm{c} 2$ & $t+\mathrm{FTB}+[\mathrm{EB} \times \mathrm{bs}]$ & $t+[\exp \times \mathrm{bs}]$ \\
\hline
\end{tabular}

Notes: The effects considered were yearly variation (denoted " $t$ "), colony (denoted "cave": "c1" and "c2" for the two levels, colony 1 and 2, respectively), breeding experience (denoted "exp": "FTB" and "EB" for the two levels, first-time breeders and experienced breeders, respectively) and the breeding success (denoted "bs"). The symbol " $X$ " was used to denote the statistical interaction between the effects. In models without an interaction effect (i.e., parallel variation), the symbol " + " was used instead. When no effects were considered (i.e., a constant value) the term "no effects considered" was used. Abbreviations are: np, number of separately estimable parameters; Dev, relative deviance; AIC, Akaike information criterion; $\Delta_{i}$, the AIC difference between the current and lowest AIC model; $w_{i}$, Akaike weight. The retained models in each step of the analysis are in boldface type.

and Anderson 2000). Model selection proceeded as follows. We first simplified the structure of $p$ keeping the structure of $\Phi$ and $\Psi$ as general as possible, i.e., as in the umbrella model. Subsequently we retained the selected structure of $p$ and conducted two separate model selection processes for $\Phi$ and $\Psi$, respectively (Grosbois and Tavecchia 2003). Here we kept the structure of the parameter that was not modeled as in the umbrella model. For example, when modeling survival, transition probabilities were assumed to vary as a function of all effects considered. This procedure minimized the bias resulting from the order in which we modeled each parameter (i.e., survival and future breeding success probabilities, Hadley et al. 2007).

\section{Results}

\section{Current reproductive success}

The model including the experience as predictor of the current breeding success was highly preferred over a model with no effect of experience (model 1, Table 1). 
TABle 2. Extended.

\begin{tabular}{|c|c|c|c|c|}
\hline $\begin{array}{c}\text { No. } \\
\text { parameters }\end{array}$ & Dev & AIC & $\Delta i$ & $w_{i}^{\prime}$ \\
\hline 201 & 3361.819 & 3763.819 & 7.143 & 0.026 \\
\hline 183 & 3398.558 & 3764.578 & 7.902 & 0.018 \\
\hline 176 & 3414.761 & 3766.761 & 10.085 & 0.006 \\
\hline 176 & 3404.676 & 3756.676 & 0.000 & 0.931 \\
\hline 173 & 3418.885 & 3764.885 & 8.209 & 0.015 \\
\hline 163 & 3441.907 & 3767.907 & 11.231 & 0.003 \\
\hline 114 & 3496.627 & 3724.627 & 4.897 & 0.041 \\
\hline 144 & 3461.133 & 3749.133 & 29.403 & 0.000 \\
\hline 112 & 3496.970 & 3720.970 & 1.240 & 0.256 \\
\hline 113 & 3495.323 & 3721.323 & 1.593 & 0.215 \\
\hline 112 & 3495.730 & 3719.730 & 0.000 & 0.476 \\
\hline 109 & 3511.523 & 3729.523 & 9.793 & 0.004 \\
\hline 108 & 3511.896 & 3727.896 & 8.166 & 0.008 \\
\hline 111 & 3513.178 & 3735.178 & 15.448 & 0.000 \\
\hline 101 & 3547.767 & 3749.767 & 30.037 & 0.000 \\
\hline 127 & 3496.847 & 3750.847 & 14.843 & 0.001 \\
\hline 143 & 3456.332 & 3742.332 & 6.328 & 0.037 \\
\hline 123 & 3507.061 & 3753.061 & 17.057 & 0.000 \\
\hline 111 & 3529.299 & 3751.299 & 15.295 & 0.000 \\
\hline 132 & 3483.053 & 3747.053 & 11.050 & 0.003 \\
\hline 131 & 3474.004 & 3736.004 & 0.000 & 0.864 \\
\hline 107 & 3531.971 & 3745.971 & 9.968 & 0.006 \\
\hline 118 & 3509.798 & 3745.798 & 9.795 & 0.006 \\
\hline 110 & 3531.615 & 3751.615 & 15.612 & 0.000 \\
\hline 101 & 3573.353 & 3775.353 & 39.350 & 0.000 \\
\hline 120 & 3500.728 & 3740.728 & 4.724 & 0.081 \\
\hline 110 & 3532.096 & 3752.096 & 16.093 & 0.000 \\
\hline 109 & 3534.091 & 3752.091 & 16.088 & 0.000 \\
\hline 99 & 3577.710 & 3775.710 & 39.706 & 0.000 \\
\hline 99 & 3579.241 & 3777.241 & 41.237 & 0.000 \\
\hline 98 & 3581.696 & 3777.696 & 41.693 & 0.000 \\
\hline 62 & 3567.098 & 3691.098 & 1.083 & 0.286 \\
\hline 63 & 3565.591 & 3691.591 & 1.576 & 0.223 \\
\hline 62 & 3566.015 & 3690.015 & 0.000 & 0.491 \\
\hline 30 & 3669.646 & 3729.646 & 39.631 & 0.000 \\
\hline 31 & 3668.101 & 3730.101 & 40.086 & 0.000 \\
\hline 30 & 3668.494 & 3728.494 & 38.479 & 0.000 \\
\hline 42 & 3645.080 & 3729.079 & 39.064 & 0.000 \\
\hline
\end{tabular}

According to this model the breeding success of the first observed breeding attempt was $\sim 10 \%$ lower than in subsequent years (46.9\% and 59.3\%, respectively).

\section{Survival and future reproductive success}

The umbrella model explained the data adequately (goodness-of-fit test: $\chi^{2}=248.737, \mathrm{df}=293, P=0.973$ ). A more realistic model without the effect of breeding success in the probability of recapture was preferred (Table 2). In agreement with a previous study (Tavecchia et al. 2008) we found that recapture probability was high and varied over time in both colonies. In cave 2 , it increased linearly over time due to the progressive occupancy of artificial nest-boxes (model 3, Table 2, Fig. 1; Tavecchia et al. 2008). The modeling of survival probabilities retained time $(w+=1)$, experience $(w+=1)$, and breeding state $(w+=0.99)$ effects as predictors of survival (models 8, 9, 10, Table 2). Such models included additive effects of time with experience and breeding success, i.e., parallel variation of survival over time among experience groups and breeding success states. Note that model 10 assumed a common survival parameter for first-time breeders regardless their current breeding success. Indeed, the effect of current breeding success among first-time breeders was the least important predictor of future survival probability $(w+=0.52)$. In future breeding success probabilities we retained the effects of time $(w+=1)$, experience $(w+=0.99)$, and of the current breeding success $(w+=0.92)$. The effect of the current breeding success on transition probabilities was retained only for first-time breeders $(w+=0.91)$ (model 20, Table 2) while among experienced breeders it was the least important predictor $(w+=0.05)$. At this stage, the selected structures of models $3,8,9,10$, and 20 were used to build the final models that considerably improved the AIC value (models 31, 32, 33; Table 2). According to these models ( 31 and 32 in Table 2), both the breeding experience and the breeding success had a positive effect on survival, although a simpler model without the effect of breeding success in first-time breeders was equally supported (model 33, Table 2). Annual averaged estimates of survival probabilities from models 31, 32, and 33 also indicated that current breeding success was not an important predictor for the survival of first-time breeders but it was for experienced breeders (Fig. 2). As for the future breeding success, averaged estimates showed that birds that survived had in general a high probability of breeding successfully the following year. Although confidence intervals overlap, the experience effect was retained by the selected models (Fig. 3). Experienced breeders had the same probability of breeding successfully the subsequent year regardless of their current breeding output. This indicated that current effort in experienced birds does not influence future breeding outputs. In contrast the effect of the current breeding success, i.e., effort, was retained in first-time breeders although averaged estimates appeared very similar (Fig. 3).

\section{DisCUSSION}

Correlative studies are not expected to correctly estimate an evolutionary link between two traits (Nichols and Kendall 1995, Viallefont et al. 1995). In absence of manipulation of the effort invested in reproduction, the cost of reproduction may indeed be masked by a quality-dependent breeding investment of individuals, where low quality individuals invest less with no apparent costs of reproduction (Reznick 1985, Van Noordwijk and Dejong 1986). Moreover, manipulative studies showed that Procellariiformes tend to transfer the unexpected costs of the current reproduction to their offspring without jeopardizing their future survival or future breeding attempt (Mauck and Grubb 1995, Mínguez 1998, Navarro and González-Solís 2007). 


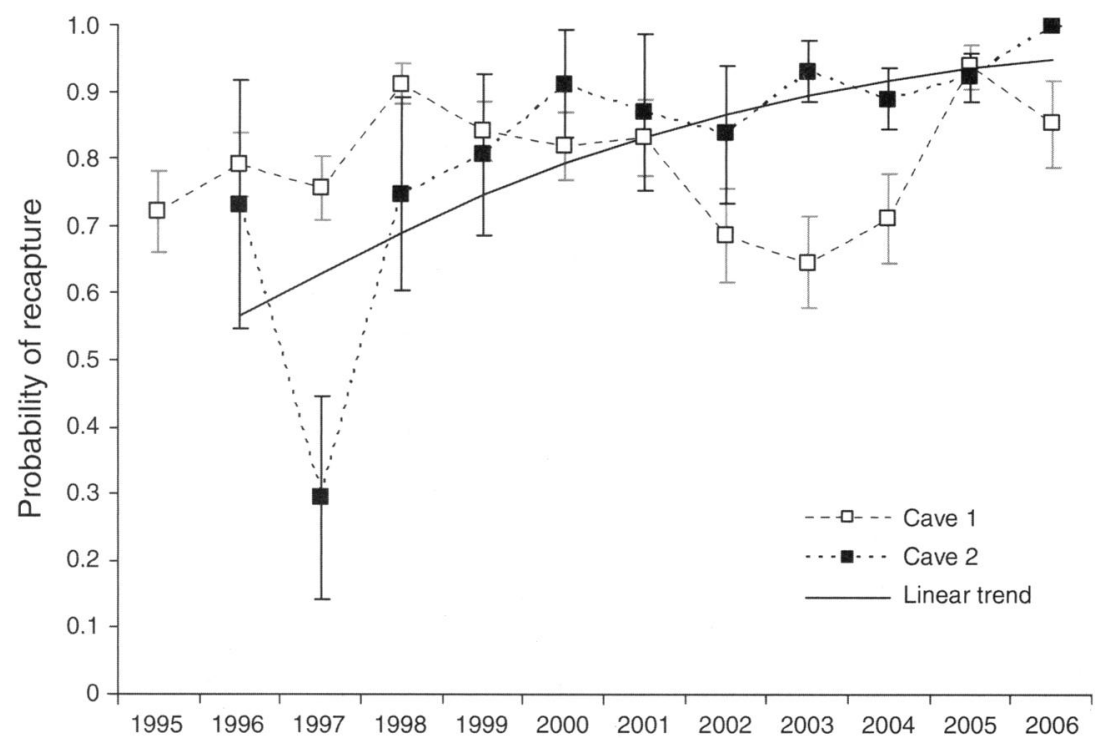

FIci. 1. Average annual estimates $( \pm$ SE) of recapture probabilities of European Storm Petrels breeding in cave 1 (open symbols) and cave 2 (solid symbols) at Benidorm Island, western Mediterranean. Estimates are from models assuming a linear trend in cave 2 (solid line) and a full time effect in cave 1 (models 31, 32, and 33; Table 2).

We did not find any indication of an overall cost of reproduction in relation to the current reproductive investment. In disagreement with the cost of reproduction hypothesis, we found that individuals that failed the current reproduction (i.e., invest less) had a lower future survival. Moreover, we did not find any evidence of a cost of reproduction on future breeding success. Individuals that survived had a higher probabilities of breeding successfully the following year likely due to a progressive selection of high-quality individuals (see also Forslund and Pärt 1995, Ratcliffe et al. 1998, Mauck et al. 2004, Barbraud and Weimerskirch 2006). In fact, we found a positive relationship between fitness compo- nents in agreement with the selection hypothesis and other correlative studies on long-lived birds (Wooller et al. 1990, Cam and Monnat 2000, Barbraud and Weimerskirch 2006, O'Dwyer et al. 2006). Apart from the heterogeneity in individual quality, the lack of survival or fecundity costs associated with high reproductive investments can also be generated by favorable environmental conditions at breeding (Erikstad et al 1998). Studies on long-lived mammals and seabirds showed that breeding probabilities and survival can be negatively influenced by poor environmental conditions (Barbraud and Weimerskirch 2005, Hadley et al. 2007). Thus, high levels of reproductive effort can generate a

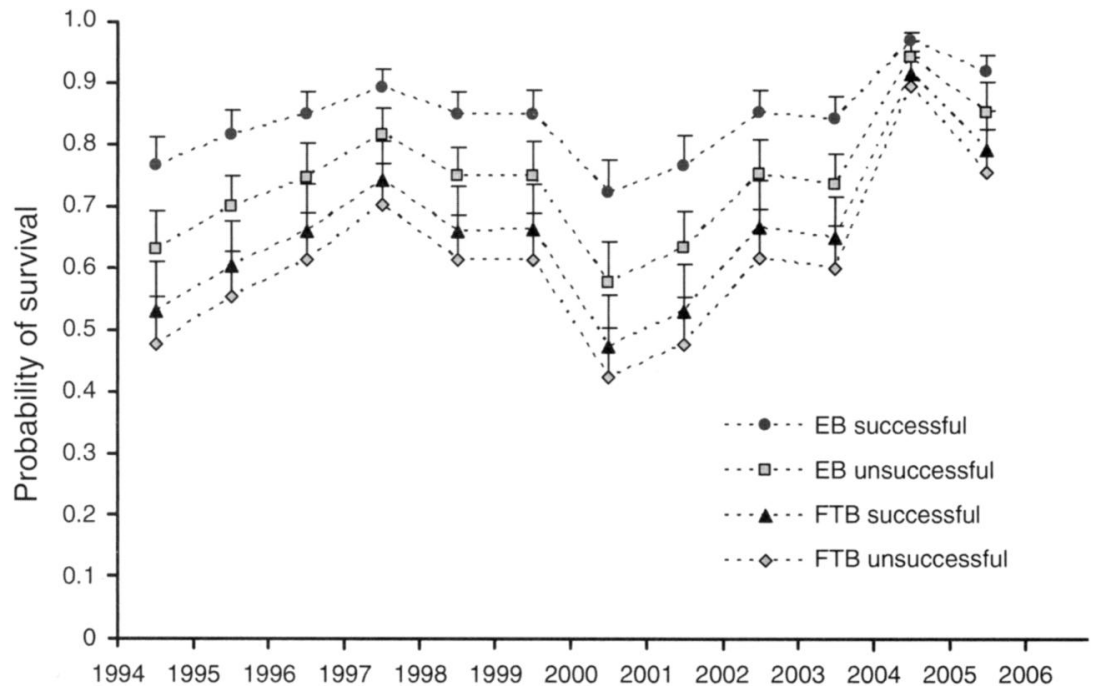

FIG. 2. Annual variation in survival probability (+SE) of European Storm Petrels averaged over models 31, 32, and 33 (see Table 2), in which survival varied among four groups: experienced and first-time breeders (EB and FTB, respectively) with successful and unsuccessful birds. 


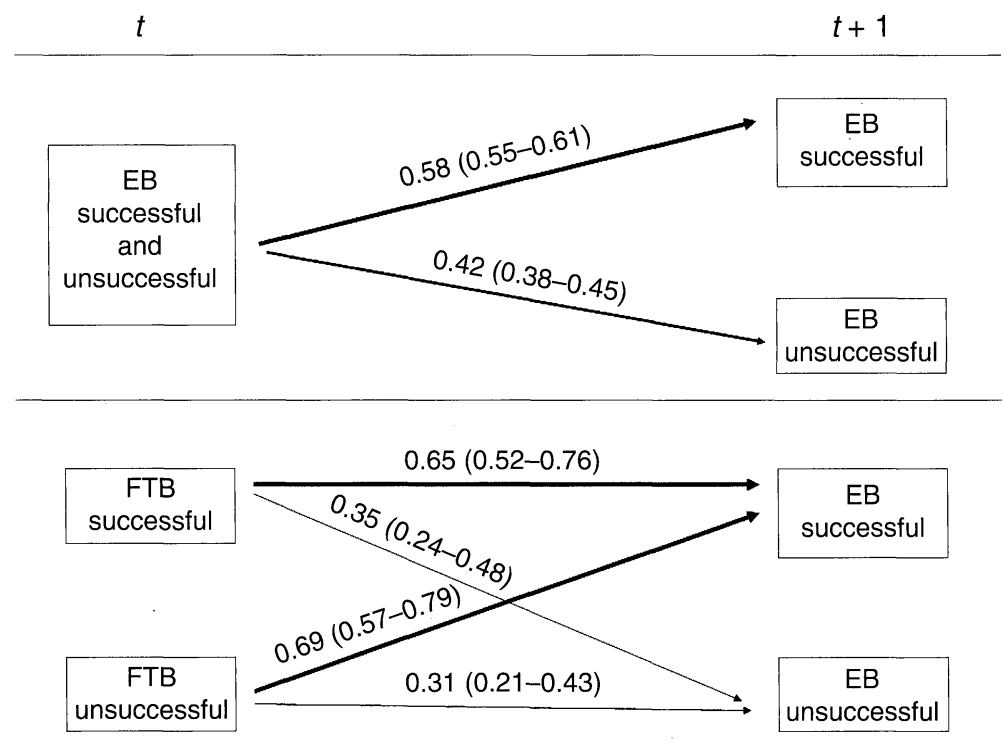

FIG. 3. Estimates (95\% confidence intervals in parentheses) of future breeding performance transition probabilities. Transition probabilities were obtained by averaging estimates from models 34, 35, and 36 (see Results and Table 2). "EB" and "FTB" denote experienced and first-time breeders, respectively.

fitness cost detectable only when resources are limited (Tavecchia et al. 2005).

\section{The influence of experience}

Results from the first reproductive attempt were the only supporting the cost of reproduction hypothesis but again unrelated to the breeding effort. In fact first-time breeders, independently of their breeding success, survived less than experienced breeders. A cost of the first reproduction on survival and reproduction has also been reported for other long-lived species of both birds and mammals (Viallefont et al. 1995, Pyle et al. 1997, Cam and Monnat 2000, Tavecchia et al. 2001, 2005, Barbraud and Weimerskirch 2005, Moyes et al. 2006, Nevoux et al. 2007), and it is probably related with the hormonal changes triggered by the first reproductive status (Harshman and Zera 2007). In addition, the lower survival of first-time breeders could reflect high proportions of low-quality individuals among this group, in accordance with the selection hypothesis (Wendeln and Becker 1999, Mauck et al. 2004, Barbraud and Weimerskirch 2006). Although survival probability in European Storm Petrels varied over the years, the survival difference between first-time and experienced breeders was constant and equal at the two study colonies, suggesting that stochastic environmental conditions may affect birds equally, independently of their breeding experience or success. Inexperienced breeders also showed an average lower current breeding success than experienced breeders, probably due to their lack of breeding experience (i.e., the breeding experience hypothesis [Ollason and Dunnet 1988, Bradley et al. 2000]) and their intrinsic lower quality (Mauck et al. 2004, Barbraud and Weimerskirch 2006). However, first-time breeders are on average younger than experienced breeders and an experience-dependent cost of reproduction can be partially confounded by a positive effect of the age per se (Nur 1984, Forslund and Pärt 1995, Tavecchia et al. 2001). Moreover, Viallefont et al. (1995) showed that young first-time breeders of Snow Goose Anser caerulescens were more likely to skip or to fail breeding the following season than older first-time breeders, and similar results have been reported for other long-lived birds (Weimerskirch 1990, Wooller et al. 1990, Barbraud and Weimerskirch 2005). Unfortunately, we were not able to fully estimate the relative effect of the age and the experience in the trade-off pattern because for most of the birds only their experience was known, but a preliminary analysis of a small set of birds of known age does not support this hypothesis (results not shown).

Strikingly we found that first-time breeders that survived showed higher probabilities of breeding successfully in the following year than experienced breeders. Nevertheless, the model selection did not suggest a strong effect. This result may be the consequence of several nonexclusive factors. First, the presence of high proportions of old birds with, expected senescence in breeding performance, in the later group (Bradley et al. 2000); second, an intensive selection process of high quality individuals during the first reproduction (Forslund and Pärt 1995, Ratcliffe et al. 1998, Mauck et al. 2004, Barbraud and Weimerskirch 2006); finally, the acquisition of breeding experience (Nur 1984, Ollason and Dunnet 1988, Bradley et al. 2000). Moreover the effect of the current breeding success on future breeding success was retained for first-time breeders, likely because those who bred unsuccessfully may have a small advantage in terms of future breeding success, in accordance with the cost of reproduction hypothesis (Roff 1992, Stearns 1992). 
Nevertheless, the model selection did not suggest a strong influence of the current breeding success.

In conclusion, results clearly supported the selection hypothesis, as unsuccessful and first-time breeders showed lower probabilities of survival than successful and experienced birds (Wooller et al. 1990, Wendeln and Becker 1999, Cam and Monnat 2000, Mauck et al. 2004 Barbraud and Weimerskirch 2006). The low survival and low initial breeding performance of first-time breeders found here suggested that the first reproduction represented a critical period, in line with other studies on birds (Viallefont et al. 1995, Pyle et al. 1997, Cam and Monnat 2000, Tavecchia et al. 2001, Barbraud and Weimerskirch 2005, Nevoux et al. 2007). Selective pressures during the first breeding event probably played an important role in the evolution of deferred breeding in long-lived species (Pyle et al. 1997). In fact, and with the exception of the first reproduction, we did not find any indication that breeding was costly for European Storm Petrels although we cannot exclude at present long-term cumulative costs of reproduction, as found in some long-lived mammals (Moyes et al. 2006). Future studies should also focus in handling among individuals heterogeneity. At present the incorporation of individual heterogeneity cannot be done using procedures based on likelihood. A possible way would be to obtained estimates based on Monte Carlo techniques (King et al. 2006) but the available methods at the moment are not flexible enough to handle complex models.

\section{ACKNOWLEDGMENTS}

We acknowledge the many people who participated in the field work over the years. We are indebted to the ward and Environmental Monitoring Service of Benidorm Island (Parque Natural Serra Gelada y su entorno litoral-Generalitat Valenciana). We are also very grateful to Remi Choquet for his invaluable help with the software. Alejandro Martínez-Abrain and three anonymous referees made constructive comments on an early draft. Ana Sanz-Aguilar was supported by a postgraduate grant (AP2004-1128) of the Spanish Ministry of Science, which also funded the study through several grants (BOS2003-01960, CGL2006-04325/BOS, and SAB2006-0014/Roger Pradel).

\section{Literature Cited}

Barbraud, C., and H. Weimerskirch. 2005. Environmental conditions and breeding experience affect costs of reproduction in Blue Petrels. Ecology 86:682-692.

Barbraud, C., and H. Weimerskirch. 2006. The trade-off between survival and reproduction in long-lived birds, and the role of individual quality. Acta Zoologica Sinica 52:101106.

Blums, P., J. D. Nichols, J. E. Hines, M. S. Lindberg, and A Mednis. 2005. Individual quality, survival variation and patterns of phenotypic selection on body condition and timing of nesting in birds. Oecologia 143:365-376.

Boulinier, T., G. Sorci, J. Clobert, and E. Danchin. 1997. An experimental study of the costs of reproduction in the Kittiwake Rissa tridactyla: comment. Ecology 78:1284-1287.

Bradley, J. S., R. D. Wooller, and I. J. Skira. 2000. Intermittent breeding in the short-tailed shearwater Puffinus tenuirostris. Journal of Animal Ecology 69:639-650

Brownie, C., J. E. Hines, J. D. Nichols, K. H. Pollock, and J. B. Hestbeck. 1993. Capture-recapture studies for multiple strata including non-Markovian transitions. Biometrics 49:11731187.

Burnham, K. P., and R. D. Anderson. 2000. Model selection and inference: a practical information theoretic approach. Springer-Verlag, New York, USA.

Cam, E., W. A. Link, E. G. Cooch, J. Y. Monnat, and E. Danchin. 2002. Individual covariation in life-history traits: seeing the trees despite the forest. American Naturalist 159: 96-105.

Cam, E., and J. Y. Monnat. 2000. Apparent inferiority of firsttime breeders in the Kittiwake: the role of heterogeneity among age classes. Journal of Animal Ecology 69:380-394.

Choquet, R., A. M. Reboulet, J. D. Lebreton, O. Gimenez, and R. Pradel. 2005. U-CARE 2.2. User manual. Mimeographed document. CEFE/CNRS, Montpellier, France.

Choquet, R., A. M. Reboulet, R. Pradel, O. Gimenez, and J. D. Lebreton. 2004. M-SURGE: new software specifically designed for multistate capture recapture models. Animal Biodiversity and Conservation 27:207-221.

Coulson, J. C., and C. Thomas. 1985. Differences in the breeding performance of individual kittiwake gulls, Rissa tridactyla, (L.). Pages 489-503 in R. M. Sibley and R. H. Smith, editors. Behavioural ecology. Blackwell Scientific Publications, Oxford, UK

Crone, E. E. 2001. Is survivorship a better fitness surrogate than fecundity? Evolution 55:2611-2614.

de León, A., and E. Mínguez. 2003. Occupancy rates and nesting success of European Storm-Petrels breeding inside artificial nest-boxes. Scientia Marina 67:109-112.

Doligez, B., J. Clobert, R. A. Pettifor, M. Rowcliffe, L. Gustafsson, C. M. Perrins, and R. H. McCleery. 2002. Costs of reproduction: assessing responses to brood size manipulation on life-history and behavioral traits using multi-state capture-recapture models. Journal of Applied Statistics 29: 407-423.

Erikstad, K. E., P. Fauchald, T. Tveraa, and H. Steen. 1998. On the cost of reproduction in long-lived birds: the influence of environmental variability. Ecology 79:1781-1788.

Forslund, P., and T. Pärt. 1995. Age and reproduction in birds: hypothesis and test. Trends in Ecology and Evolution 10: $374-378$.

Fox, C. W., D. A. Roff, and D. J. Fairbairn. 2001 Evolutionary ecology concepts and case studies. Oxford University Press, Oxford, UK.

Grosbois, V., and G. Tavecchia. 2003. Modeling dispersal with capture-recapture data: disentangling decisions of leaving and settlement. Ecology 84:1225-1236.

Hadley, G. L., J. J. Rotella, and R. A. Garrott. 2007. Evaluation of reproductive costs for Weddell seals in Erebus Bay, Antarctica. Journal of Animal Ecology 76:448-458.

Harshman, L. G., and A. J. Zera. 2007. The cost of reproduction: the devil in the details. Trends in Ecology and Evolution 22:80-86.

Jenouvrier, S., C. Barbraud, B. Cazelles, and H. Weimerskirch. 2005. Modelling population dynamics of seabirds: importance of the effects of climate fluctuations on breeding proportions. Oikos 108:511-522.

King, R., S. P. Brooks, B. J. T. Morgan, and T. Coulson. 2006. Factors influencing soay sheep survival: a Bayesian analysis. Biometrics 62:211-220.

Lebreton, J. D., K. P. Burnham, J. Clobert, and D. R. Anderson. 1992. Modeling survival and testing biological hypotheses using marked animals: a unified approach with case-studies. Ecological Monographs 62:67-118.

Lebreton, J. D., and R. Pradel. 2002. Multistate recapture models: modelling incomplete individual histories. Journal of Applied Statistics 29:353-369.

Mauck, R. A., and T. C. Grubb. 1995. Petrel parents shunt all experimentally increased reproductive costs to their offspring. Animal Behavior 49:999-1008. 
Mauck, R. A., C. E. Huntington, and T. C. Grubb. 2004. Agespecific reproductive success: evidence for the selection hypothesis. Evolution 58:880-885.

McCulloch, C. E., and S. R. Searle. 2001. Generalized, linear, and mixed models. John Wiley and Sons, New York, New York, USA

McNamara, J. M., and A. I. Houston. 1996. State-dependent life histories. Nature 380:215-221

Mínguez, E. 1994. Censo, cronología de puesta y éxito reproductor del páño común (Hydrobates pelagicus) en la Isla de Benidorm (Alicante E de España). Ardeola 41:3-11.

Mínguez, E. 1996. Nestling feeding strategy of the British Storm-Petrel Hydrobates pelagicus in a Mediterranean colony. Journal of Zoology 239:633-643.

Mínguez, E. 1998. The costs of incubation in the British StormPetrel: an experimental study in a single-egg layer. Journal of Avian Biology 29:183-189.

Moyes, K., T. Coulson, B. J. T. Morgan, A. Donald, S. J Morris, and T. H. Clutton-Brock. 2006. Cumulative reproduction and survival costs in female red deer. Oikos 115:241252.

Navarro, J., and J. González-Solís. 2007. Experimental increase of flying costs in a pelagic seabird: effects on foraging strategies, nutritional state and chick condition. Oecologia 151:150-160.

Nevoux, M., H. Weimerskirch, and C. Barbraud. 2007. Environmental variation and experience-related differences in the demography of the long-lived Black-browed Albatross. Journal of Animal Ecology 76:159-167.

Nichols, J. D., J. E. Hines, K. H. Pollock, R. L. Hinz, and W. A. Link. 1994. Estimating breeding proportions and testing hypothesis about costs of reproduction with capturerecapture data. Ecology 75:2052-2065.

Nichols, J. D., and W. L. Kendall. 1995. The use of multi-state capture-recapture models to address questions in evolutionary ecology. Journal of Applied Statistics 22:835-846.

Nur, N. 1984. Increased reproductive success with age in the California Gull: due to increased effort or improvement of skill? Oikos 43:407-408.

Nur, N. 1988. The consequences of brood size for breeding Blue Tits. III. Measuring the cost of reproduction: survival, future fecundity, and differential dispersal. Evolution 42:351-362.

O'Dwyer, T. W., W. A. Buttemer, D. A. Priddel, and J. A Downing. 2006. Prolactin, body condition and the cost of good parenting: an interyear study in a long-lived seabird, Gould's Petrel (Pterodroma leucoptera). Functional Ecology 20:806-811.

Ollason, J. C., and G. M. Dunnet. 1988. Variation in reproductive success in Fulmars. Pages 268-278 in T. H Clutton-Brock, editor. Studies in individual variation in contrasting breeding systems. University of Chicago Press, Chicago, Illinois, USA.

Orzack, S. H., and S. Tuljapurkar. 2001. Reproductive effort in variable environments, or environmental variation is for the birds. Ecology 82:2659-2665.

Pradel, R., C. M. A. Wintrebert, and O. Gimenez. 2003. A proposal for a goodness-of-fit test to the Arnason-Schwarz multisite capture-recapture model. Biometrics 59:43-53.

Pyle, P., N. Nur, W. J. Sydeman, and S. D. Emslie. 1997. Cost of reproduction and the evolution of deferred breeding in the western gull. Behavioural Ecology 8:140-147.

Ratcliffe, N., P. Catry, K. C. Hamer, N. I. Klomp, and R. W. Furness. 2002. The effect of age and year on the survival of breeding adult Great Skuas Catharacta skua in Shetland. Ibis 144:384-392.
Ratcliffe, N., R. W. Furness, and N. I. Klomp. 1998. Influences of breeding experience on the reproductive performance of Great Skuas Catharacta skua. Journal of Avian Biology 29: 293-298.

Reid, J. M., E. M. Bignal, S. Bignal, D. I. McCracken, and P. Monaghan. 2003. Age-specific reproductive performance in red-billed choughs Pyrrhocorax pyrrhocorax: patterns and processes in a natural population. Journal of Animal Ecology 72:765-776.

Reznick, D. 1985. Cost of reproduction: an evaluation of the empirical evidence. Oikos 44:267.

Reznick, D. 1992. Measuring the costs of reproduction. Trends in Ecology and Evolution 7:42-45.

Reznick, D., L. Nunney, and A. Tessier. 2000. Big houses, big cars, superfleas and the costs of reproduction. Trends in Ecology and Evolution 15:421-425.

Roff, D. A. 1992. The evolution of life histories. Chapman and Hall, New York, New York, USA.

Saether, B. E., and O. Bakke. 2000. Avian life history variation and contribution of demographic traits to the population growth rate. Ecology 81:642-653.

Schwarz, C. J., J. F. Schweigert, and A. N. Arnason. 1993. Estimating migration rates using tag-recovery data. Biometrics 49:177-193.

Stearns, S. C. 1992. The evolution of life histories. Oxford University Press, Oxford, UK.

Stevenson, I. R., and D. R. Bancroft. 1995. Fluctuating tradeoffs favour precocial maturity in male Soay sheep. Proceedings of the Royal Society B 262:267-275.

Tavecchia, G., T. Coulson, B. J. T. Morgan, J. M. Pemberton, J. C. Pilkington, F. M. D. Gulland, and T. H. Clutton-Brock 2005. Predictors of reproductive cost in female Soay sheep Journal of Animal Ecology 74:201-213.

Tavecchia, G., E. Mínguez, A. de León, M. Louzao, and D. Oro. 2008. Living close, doing differently: small-scale asynchrony in demographic parameters in two species of seabirds. Ecology 89:77-85.

Tavecchia, G., R. Pradel, V. Boy, A. R. Johnson, and F. Cezilly. 2001. Sex- and age-related variation in survival and cost of first reproduction in Greater Flamingos. Ecology 82: $165-174$.

Van Noordwijk, A. J., and G. Dejong. 1986. Acquisition and allocation of resources: their influence on variation in lifehistory tactics. American Naturalist 128:137-142.

Viallefont, A., F. Cooke, and J. D. Lebreton. 1995. Age-specific costs of first-time breeding. Auk 112:67-76.

Warham, J. 1990. The petrels: their ecology and breeding systems. Academic Press, London, UK.

Warham, J. 1996. The behaviour, population biology and physiology of the petrels. Academic Press, London, UK

Weimerskirch, H. 1990. The influence of age and experience on breeding performance of the Antarctic Fulmar, Fulmarus glacialoides. Journal of Animal Ecology 59:867-875.

Wendeln, H., and P. H. Becker. 1999. Effects of parental quality and effort on the reproduction of Common Terns. Journal of Animal Ecology 68:205-214

Wernham, C. V., and D. M. Bryant. 1998. An experimental study of reduced parental effort and future reproductive success in the puffin, Fratercula arctica. Journal of Animal Ecology 67:25-40.

Wooller, R. D., J. S. Bradley, I. J. Skira, and D. L. Serventy. 1990. Reproductive success of Short-tailed Shearwaters Puffinus tenuirostris in relation to their age and breeding experience. Journal of Animal Ecology 59:161-170. 